\title{
Coal to gas: the influence of methane leakage
}

\author{
Tom M. L. Wigley
}

Received: 19 May 2011 / Accepted: 10 August 2011 / Published online: 26 August 2011

(C) Springer Science+Business Media B.V. 2011

\begin{abstract}
Carbon dioxide $\left(\mathrm{CO}_{2}\right)$ emissions from fossil fuel combustion may be reduced by using natural gas rather than coal to produce energy. Gas produces approximately half the amount of $\mathrm{CO}_{2}$ per unit of primary energy compared with coal. Here we consider a scenario where a fraction of coal usage is replaced by natural gas (i.e., methane, $\mathrm{CH}_{4}$ ) over a given time period, and where a percentage of the gas production is assumed to leak into the atmosphere. The additional $\mathrm{CH}_{4}$ from leakage adds to the radiative forcing of the climate system, offsetting the reduction in $\mathrm{CO}_{2}$ forcing that accompanies the transition from coal to gas. We also consider the effects of: methane leakage from coal mining; changes in radiative forcing due to changes in the emissions of sulfur dioxide and carbonaceous aerosols; and differences in the efficiency of electricity production between coal- and gas-fired power generation. On balance, these factors more than offset the reduction in warming due to reduced $\mathrm{CO}_{2}$ emissions. When gas replaces coal there is additional warming out to 2,050 with an assumed leakage rate of $0 \%$, and out to 2,140 if the leakage rate is as high as $10 \%$. The overall effects on global-mean temperature over the 21 st century, however, are small.
\end{abstract}

Hayhoe et al. (2002) have comprehensively assessed the coal-to-gas issue. What has changed since then is the possibility of substantial methane production by high volume hydraulic fracturing of shale beds ("fracking") and/or exploitation of methane reservoirs in near-shore ocean sediments. Fracking, in particular, may be associated with an increase in the amount of attendant gas leakage compared with other means of gas production (Howarth et al. 2011). In Hayhoe et al., the direct effects on global-mean temperature of differential gas leakage between coal and gas production are very small (see their Fig. 4). Their estimates of gas

Electronic supplementary material The online version of this article (doi:10.1007/s10584-011-0217-3) contains supplementary material, which is available to authorized users.

T. M. L. Wigley $(\bowtie)$

National Center for Atmospheric Research, Post Office Box 3000, Boulder, CO 80307-3000, USA

e-mail: wigley@ucar.edu

T. M. L. Wigley

University of Adelaide, Adelaide, South Australia, Australia 
leakage, however, are less than more recent estimates. Here, we extend and update the analysis of Hayhoe et al. to examine the potential effects of gas leakage on the climate, and on uncertainties arising from uncertainties in leakage percentages.

We begin with a standard "no-climate-policy" baseline emissions scenario, viz. the MiniCAM Reference scenario (MINREF below) from the CCSP2.1a report (Clarke et al. 2007). (Hayhoe et al. used the MiniCAM A1B scenario, Nakićenović and Swart 2000.) We chose MINREF partly because it is a more recent "no-policy" scenario, but also because there is an extended version of MINREF that runs beyond 2,100 out to 2,300 (Wigley et al. 2009). The longer time horizon is important because of the long timescales involved in the carbon cycle where changes to $\mathrm{CO}_{2}$ emissions made in the 21 st century can have effects extending well into the 22nd century. (A second baseline scenario, the MERGE Reference scenario from the CCSP2.1a report, is considered in the Electronic Supplementary Material).

In MINREF, coal combustion provides from 38\% (in 2010) to 51\% (in 2100) of the emissions of $\mathrm{CO}_{2}$ from fossil fuels. (The corresponding percentages for gas are 19 to $21 \%$, and for oil are 43 to $28 \%$.) For our coal-to-gas scenario we start with their contributions to energy. It is important here to distinguish between primary energy (i.e., the energy content of the resource) and final energy (the amount of energy delivered to the user at the point of production). For a transition from coal to gas, we assume that there is no change in final energy. As electricity generation from gas is more efficient than coal-fired generation, the increase in primary energy from gas will be less than the decrease in primary energy from coal - the differential depends on the relative efficiencies with which energy is produced.

To calculate the change in fossil $\mathrm{CO}_{2}$ emissions for any transition scenario we use the following relationship relating $\mathrm{CO}_{2}$ emissions to primary energy $(\mathrm{P}) \ldots$

$$
\mathrm{ECO} 2=\mathrm{A} \text { Pcoal }+\mathrm{B} \text { Poil }+\mathrm{C} \text { Pgas }
$$

where $\mathrm{A}, \mathrm{B}$ and $\mathrm{C}$ are representative emissions factors (emissions per unit of primary energy) for coal, oil and gas. The emissions factors relative to coal that we use are 0.75 for oil and 0.56 for gas, based on information in EPA's AP-42 Report (EPA 2005). Using the MINREF emissions for $\mathrm{CO}_{2}$ and the published primary energy data give a best fit emissions factor for coal of $0.027 \mathrm{GtC} /$ exajoule, well within the uncertainty range for this term.

To determine the change in $\mathrm{CO}_{2}$ emissions in moving from coal to gas under the constraint of no change in final energy we use the equivalent of Eq. (1) expressed in terms of final energy (F). This requires knowing the efficiencies for energy production from coal, oil and gas (i.e., final energy/primary energy). If $\mathrm{F}=\mathrm{P} \times($ efficiency), then we have

$$
\mathrm{ECO} 2=(\mathrm{A} / \mathrm{a}) \text { Fcoal }+(\mathrm{B} / \mathrm{b}) \text { Foil }+(\mathrm{C} / \mathrm{c}) \text { Fgas }
$$

where $\mathrm{a}, \mathrm{b}$ and $\mathrm{c}$ are the efficiencies for energy production from coal, oil and gas. For changes in final energy $(\Delta F)$ in the coal-to-gas case, $\Delta$ Foil is necessarily zero. To keep final energy unchanged, therefore, we must have $\Delta$ Fgas $=-\Delta$ Fcoal. Hence, from Eq. (2)

$$
\Delta \mathrm{ECO} 2=(\Delta \mathrm{Fcoal})(\mathrm{A} / \mathrm{a}-\mathrm{C} / \mathrm{c})
$$

or ...

$$
\Delta \mathrm{ECO} 2=\mathrm{A} \Delta \mathrm{P} \operatorname{coal}[1-(\mathrm{C} / \mathrm{A}) /(\mathrm{c} / \mathrm{a})]
$$

As $\Delta$ Pcoal is negative, the first term here is the reduction in $\mathrm{CO}_{2}$ emissions from the reduction in coal use, while the second term is the partially compensating increase in $\mathrm{CO}_{2}$ 
emissions from the increase in gas use. Our best-fit value for $\mathrm{A}$ is $0.027 \mathrm{GtC} /$ exajoule, and $\mathrm{C} / \mathrm{A}=0.56$. To apply Eq. (4) we need to determine a reasonable value for the relative gas-tocoal efficiency ratio (c/a), which we assume does not change appreciably over time. For electricity generation, the primary sector for coal-to-gas substitution, Hayhoe et al. (2002, Table 2) give representative efficiencies of $32 \%$ for coal and $60 \%$ for gas. Using these values, Eq. (4) becomes ...

$$
\Delta \mathrm{ECO} 2=0.027 \Delta \mathrm{Pcoal}[1-0.299]
$$

for $\triangle \mathrm{ECO} 2$ in $\mathrm{GtC}$ and $\Delta \mathrm{P}$ in exajoules. Thus, for a unit reduction in coal emissions, there is an increase in emissions from gas combustion of about 0.3 units.

To complete our calculations, we need to estimate the changes in methane, sulfur dioxide and black carbon emissions that would follow the coal-to-gas conversion. Consider methane first. Methane is emitted to the atmosphere as a by-product of coal mining and gas production. Although these fugitive emissions are relatively small, they are important because methane is a far more powerful forcing agent per unit mass than $\mathrm{CO}_{2}$.

For coal mining we use information from Spath et al. (1999; Figs. C1 and C4). A typical US coal-fired power plant emits $1,100 \mathrm{gCO} 2 / \mathrm{kWh}$, with an attendant release of methane of $2.18 \mathrm{gCH} 4 / \mathrm{kWh}$, almost entirely from mining. Thus, for each $\mathrm{GtC}$ of $\mathrm{CO}_{2}$ emitted from a coal-fired power plant, $7.27 \mathrm{TgCH} 4$ are emitted from mining. Spath et al. give other information that can used to check the above result. They give values of $1.91 \mathrm{gCH} 4$ released per ton of coal mined from surface mines, and $4.23 \mathrm{gCH} 4$ per ton from deep mines. As $65 \%$ of coal comes from deep mines, the weighted average release is $3.42 \mathrm{gCH} 4 /$ ton. Since 1 ton of coal, when burned, typically produces $1.83 \mathrm{kgCO} 2$, the amount of fugitive methane per $\mathrm{GtC}$ of $\mathrm{CO}_{2}$ emissions from coal-fired power plants is $6.85 \mathrm{TgCH} 4 /$ $\mathrm{GtC}$, consistent with the previous result. For our calculations we use the average of these two results, $7.06 \mathrm{TgCH} 4 / \mathrm{GtC}$; i.e., if $\mathrm{CO}_{2}$ emissions from coal-fired power generation are reduced by $1 \mathrm{GtC}$, we assume a concomitant decrease in $\mathrm{CH}_{4}$ emissions of $7.06 \mathrm{TgCH} 4$. We assume that this value for the USA is applicable for other countries.

For leakage associated with gas extraction and transport we note that every $\mathrm{kg}$ of gas burned produces $12 / 16 \mathrm{kgC}$ of $\mathrm{CO}_{2}$. If the leakage rate is "p" percent, then, for any given increase in $\mathrm{CO}_{2}$ emissions from gas combustion, the amount of fugitive methane released is $(\mathrm{p} / 100)(16 / 12) 1000=13.33$ (p) TgCH4/GtC. For a leakage rate of 2.5\%, for example (roughly the present leakage rate for conventional gas extraction), this is $33.3 \mathrm{TgCH} 4 / \mathrm{GtC}$. Because the $\mathrm{CO}_{2}$ emissions change from gas combustion is much less than that for coal (about 30\%; see Eq. (5)), for the 2.5\% leakage case this would make the coal mining and gas leakage effects on $\mathrm{CH}_{4}$ quite similar (but of opposite sign), in accord with Hayhoe et al. (2002, Table 1).

$\mathrm{SO}_{2}$ emissions are important because coal combustion produces substantial $\mathrm{SO}_{2}$, whereas $\mathrm{SO}_{2}$ emissions from gas combustion are negligible. Reducing energy production from coal has compensating effects - reduced $\mathrm{CO}_{2}$ emissions leads to reduced warming in the long term, but this is offset by the effects of reduced $\mathrm{SO}_{2}$ emissions which lead to lower aerosol loadings in the atmosphere and an attendant warming (Wigley 1991). For $\mathrm{CO}_{2}$ and $\mathrm{SO}_{2}$, emissions factors for coal (from Hayhoe et al. 2002, Table 1) are $25 \mathrm{kgC} / \mathrm{GJ}$ and $0.24 \mathrm{kgS} / \mathrm{GJ}$. For each $\mathrm{GtC}$ of $\mathrm{CO}_{2}$ produced from coal combustion, therefore, there will be 19.2 $\mathrm{TgS}$ of $\mathrm{SO}_{2}$ emitted. We can check this using emissions factors from Spath et al. (1999, Figs. C1 and C2). For a typical coal-fired power plant these are $7.3 \mathrm{gSO} 2 / \mathrm{kWh}$ and $1,100 \mathrm{gCO} 2 / \mathrm{kWh}$. Hence, for each $\mathrm{GtC}$ of $\mathrm{CO}_{2}$ produced from coal combustion, $\mathrm{SO}_{2}$ emissions will be $12.17 \mathrm{TgS}$. Effective global emissions factors can also be obtained from 
published emissions scenarios. For example, for changes over 2000 to 2010 in the MINREF scenario, the emissions factor for coal combustion is approximately $11.6 \mathrm{TgS} / \mathrm{GtC}$.

From these different estimates it is clear that there is considerable uncertainty in the $\mathrm{SO}_{2}$ emissions factor, echoing in part the widely varying sulfur contents in coal. Furthermore, for future emissions from coal combustion the $\mathrm{SO}_{2}$ emissions factor is likely to decrease markedly due to the imposition of $\mathrm{SO}_{2}$ pollution controls (as explained, for example, in Nakićenović and Swart 2000). It is difficult to quantify this effect, a difficulty highlighted, for example, by the fact that, in the second half of the 21 st century, many published scenarios show increasing $\mathrm{CO}_{2}$ emissions, but decreasing $\mathrm{SO}_{2}$ emissions - with large differences between scenarios in the relative changes.

For the coal-to-gas transition, it is not at all clear how to account for the effects that $\mathrm{SO}_{2}$ pollution controls, that will likely go on in parallel with any transition from coal to gas, will have on the $\mathrm{SO}_{2}$ emissions factor. However, future coal-fired plants will certainly employ such controls, so emissions factors for $\mathrm{SO}_{2}$ will decrease over time. To account for this we assume a value of $12 \mathrm{TgS} / \mathrm{GtC}$ for the present (2010) declining linearly to $2 \mathrm{TgS} / \mathrm{GtC}$ by 2,060 and remaining at this level thereafter. This limit and the attainment date are consistent with the fact that many of the SRES scenarios tend to stabilize $\mathrm{SO}_{2}$ emissions at a finite, non-zero value at around this time.

For black carbon (BC) aerosol emissions we use the relationship between $\mathrm{BC}$ and $\mathrm{SO}_{2}$ emissions noted by Hayhoe et al. (2002, p. 125) and make BC forcing proportional to $\mathrm{SO}_{2}$ emissions. Using best-estimate forcings from the IPCC Fourth Assessment Report, this means that the increase in sulfate aerosol forcing changes due to $\mathrm{SO}_{2}$ emissions reductions are reduced by approximately $30 \%$ by the attendant changes in $\mathrm{BC}$ emissions. This is a larger BC effect than in Hayhoe et al. However, compared with the large overall uncertainty in aerosol forcing, the difference between what we obtain here and the results of Hayhoe et al. are relatively small.

For our coal-to-gas emissions scenario we assume that primary energy from coal is reduced linearly (in percentage terms) by $50 \%$ over 2010 to $2050(1.25 \% / \mathrm{yr})$, and that the reduction in final energy is made up by extra energy from gas combustion. (A second, more extreme scenario is considered in the Electronic Supplementary Material). In this way, there are no differences in final energy between the MINREF baseline scenario and the coal-togas perturbation scenario. Hayhoe et al. consider scenarios where coal production reduces by $0.4,1.0$ and $2.0 \% / y r$ over 2000 to 2025 . After 2050 we assume no further percentage reduction in coal-based energy (i.e., the reduction in emissions from coal relative to the baseline scenario remains at 50\%). This is an idealized scenario, but it is sufficiently realistic to be able to assess the relative importance of different gas leakage rates. We consider leakage rates of zero to $10 \%$,

Baseline and perturbed (coal to gas) primary energy scenarios for coal and gas are shown in Fig. 1, together with the corresponding fossil-fuel $\mathrm{CO}_{2}$ emissions. The changes in primary energy breakdown are large: e.g., in 2100 , primary energy from coal is $37 \%$ more than from gas in the baseline case, but $50 \%$ less than gas in the perturbed case. The corresponding reduction in emissions is less striking. In the perturbed case, 2100 emissions are reduced only by $19 \%$. (Cases where there are larger emissions reductions are considered in the Electronic Supplementary Material).

To determine the consequences of the coal-to-gas scenario we use the MAGICC coupled gas-cycle/upwelling-diffusion climate model (Wigley et al. 2009; Meinshausen et al. 2011). These are full calculations from emissions through concentrations and radiative forcing to global-mean temperature consequences. We do not make use of Global Warming Potentials (as in Howarth et al. 2011, for example), which are a poor substitute for a full calculation 
Fig. 1 a Primary energy scenarios. Baseline data to 2100 are from the CCSP2.1a MiniCAM Reference scenario. After 2100, baseline primary energy data have been constructed to be consistent with emissions data in the extended MiniCAM Reference scenario (Wigley et al. 2009 - REFEXT). Full lines are for coal, dotted lines are for gas. "NEW" data correspond to the coal-to-gas scenario. Under the final energy constraint that $\Delta \mathrm{Fgas}=-\Delta \mathrm{Fcoal}$, $\Delta$ Pgas $=-(\mathrm{a} / \mathrm{c}) \Delta$ Pcoal $=-0.533$ $\Delta$ Pcoal. b Corresponding fossil $\mathrm{CO}_{2}$ emissions data

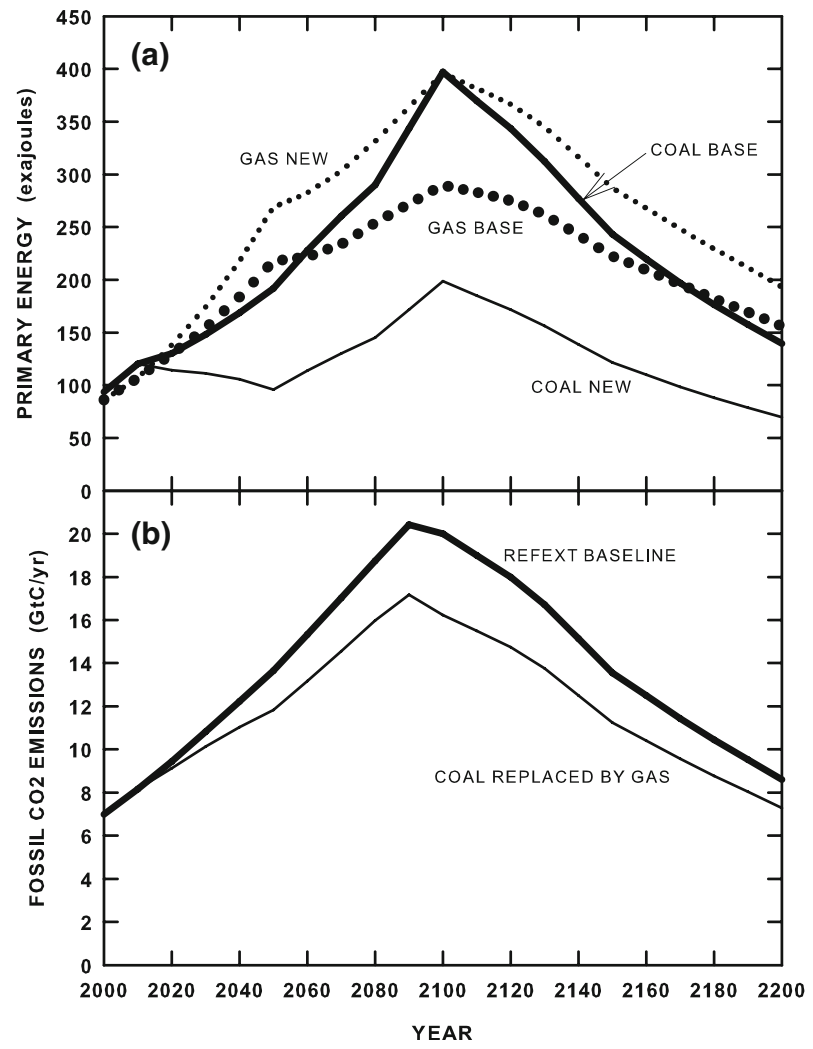

(see, e,g., Smith and Wigley 2000a, b). MAGICC considers all important radiative forcing factors, and has a carbon cycle model that includes climate feedbacks on the carbon cycle. Methane lifetime is affected by atmospheric loadings on methane, carbon monoxide, nitrogen oxides (NOx) and volatile organic compounds. The effects of methane on tropospheric ozone and stratospheric water vapor are considered directly. For component forcing values we use central estimates as given in the IPCC Fourth Assessment Report (IPCC 2007, p.4). We also assume a central value for the climate sensitivity of $3^{\circ} \mathrm{C}$ equilibrium warming for a $\mathrm{CO}_{2}$ doubling. (A second case using a higher sensitivity is considered in the Electronic Supplementary Material).

Figure 2 shows the relative and total effects of the coal-to-gas transition for a leakage rate of $5 \%$. This is within the estimated leakage rate range (1.7-6.0\%; Howarth et al. 2011) for conventional methane production (the effects of well site leakage, liquid uploading and gas processing, and transport, storage and processing). For methane from shale, Howarth et al. estimate an additional leakage of $1.9 \%$ (their Table 2 ) with a range of $0.6-3.2 \%$ (their Table 1). The zero to $10.0 \%$ leakage rate range considered here spans these estimates although we note that the high estimates of Howarth et al. have been criticized (Ridley 2011, p. 30).

The top panel of Fig. 2 shows that the effects of $\mathrm{CH}_{4}$ leakage and reduced aerosol loadings that go with the transition from coal to gas can appreciably offset the effect of reduced $\mathrm{CO}_{2}$ concentrations, potentially (see Fig. 3) until well into the 22nd century. For the leakage rate ranges considered here, however, the overall effects of the coal to 
gas transition on global-mean temperature are very small throughout the 21 st century, both in absolute and relative terms (see Fig. 2a). This is primarily due to the relatively small reduction in $\mathrm{CO}_{2}$ emissions that is effected by the transition away from coal (see Fig. 1b). Cases where the $\mathrm{CO}_{2}$ emissions reductions are larger (due to a more extreme substitution scenario, or a different baseline) are considered in the Electronic Supplementary Material. The relative contributions to temperature change are similar, but the magnitudes of temperature change scale roughly with the overall reduction in $\mathrm{CO}_{2}$ emissions.

Figure 3 shows the sensitivity of the temperature differential to the assumed leakage rate. The $\mathrm{CO}_{2}$ and aerosol terms are independent of the assumed leakage rate, so we only show the methane and total-effect results. These results are qualitatively similar to those of Hayhoe et al. who considered only a single leakage rate case (corresponding approximately to our $2.5 \%$ leakage case). For leakage rates of more than $2 \%$, the methane leakage contribution is positive (i.e., replacing coal by gas produces higher methane concentrations) - see the "CH4 COMPONENT" curves in Fig. 3. Depending on leakage rate, replacing coal by gas leads, not to cooling, but to additional warming out to between 2,050 and 2,140. Initially, this is due mainly to the influence of $\mathrm{SO}_{2}$ emissions changes, with the effects of $\mathrm{CH}_{4}$ leakage becoming more important over time. Even with zero leakage from gas production, however, the cooling that eventually arises from the coal-togas transition is only a few tenths of a $\operatorname{degC}$ (greater for greater climate sensitivity - see Electronic Supplementary Material). Using climate amelioration as an argument for the

Fig. 2 a Baseline global-mean warming (solid bold line) from the extended CCSP2.1a MiniCAM reference scenario together with the individual and total contributions due to reduced $\mathrm{CO}_{2}$ concentrations, reduced aerosol loadings and increased methane emissions for the case of 5\% methane leakage. The bold dashed line gives the result for all three components, the dotted line shows the effect of $\mathrm{CO}_{2}$ alone. The top two thin lines show the $\mathrm{CH}_{4}$ and aerosol components. b Detail showing differences from the baseline

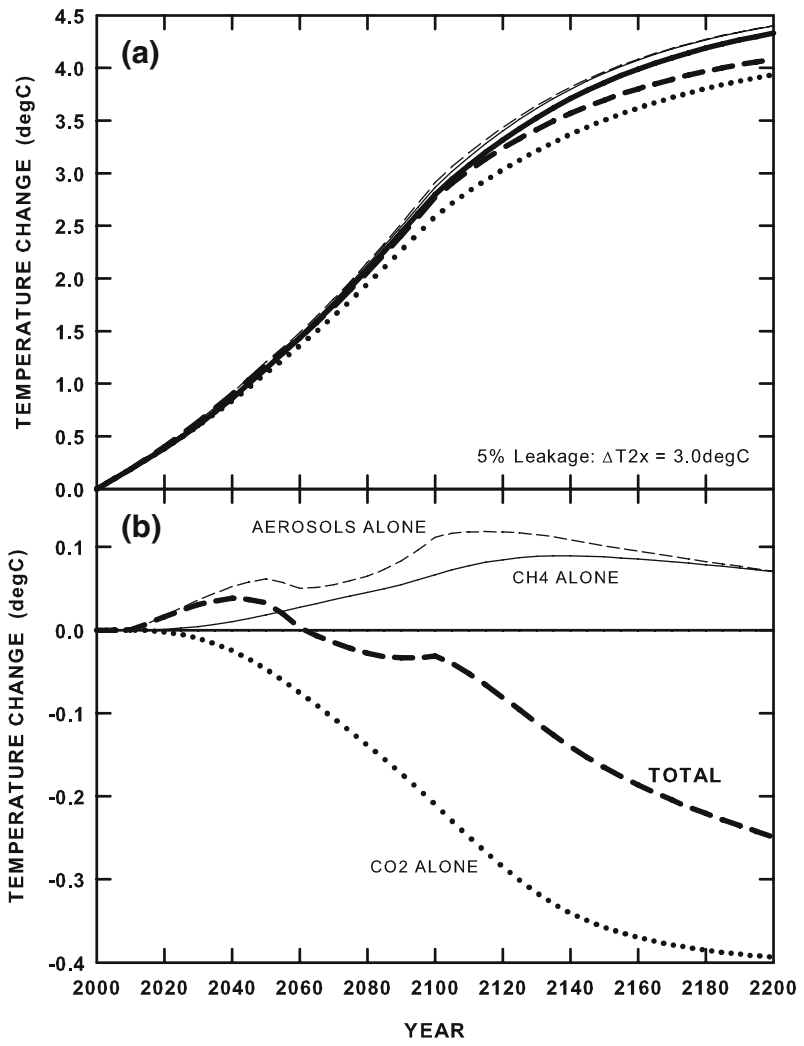


Fig. 3 The effects of different methane leakage rates on globalmean temperature. The top four curves (CH4 COMPONENT) show the effects of methane concentration changes, while the bottom four curves (TOTAL) show the total effects of methane changes, aerosol changes and $\mathrm{CO}_{2}$ concentration changes. The latter two effects are independent of the leakage rate, and are shown in Fig. 2. Results here are for a climate sensitivity of $3.0^{\circ} \mathrm{C}$

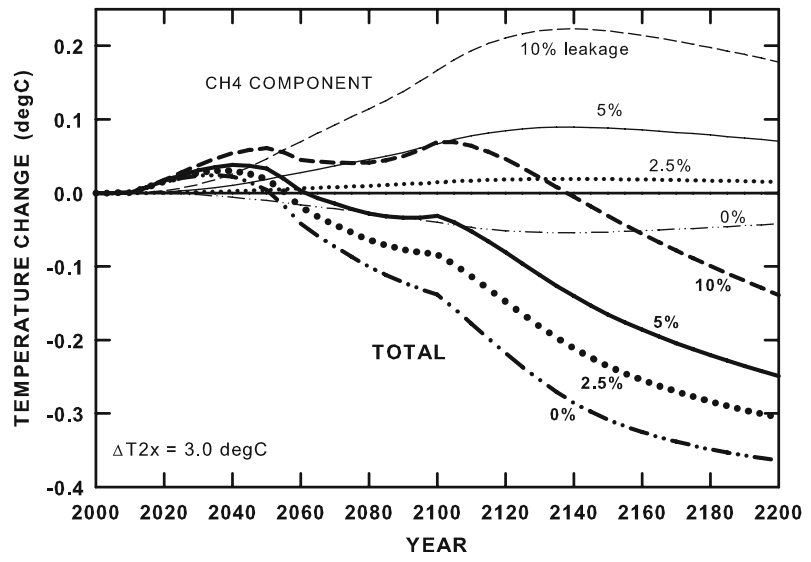

transition is, at best, a very weak argument, as noted by Hayhoe et al. (2002), Howarth et al. (2011) and others.

In summary, our results show that the substitution of gas for coal as an energy source results in increased rather than decreased global warming for many decades out to the mid 22nd century for the 10\% leakage case. This is in accord with Hayhoe et al. (2002) and with the less well established claims of Howarth et al. (2011) who base their analysis on Global Warming Potentials rather than direct modeling of the climate. Our results are critically sensitive to the assumed leakage rate. In our analysis, the warming results from two effects: the reduction in $\mathrm{SO}_{2}$ emissions that occurs due to reduced coal combustion; and the potentially greater leakage of methane that accompanies new gas production relative to coal. The first effect is in accord with Hayhoe et al. In Hayhoe et al., however, the methane effect is in the opposite direction to our result (albeit very small). This is because our analyses use more recent information on gas leakage from coal mines and gas production, with greater leakage from the latter. The effect of methane leakage from gas production in our analyses is, nevertheless, small and less than implied by Howarth et al.

Our coal-to-gas scenario assumes a linear decrease in coal use from zero in 2010 to $50 \%$ reduction in 2050, continuing at 50\% after that. Hayhoe et al. consider linear decreases from zero in 2000 to 10, 25 and 50\% reductions in 2025. If these authors assumed constant reduction percentages after 2025 , then their high scenario is very similar to our scenario.

In our analyses, the temperature differences between the baseline and coal-to-gas scenarios are small (less than $0.1^{\circ} \mathrm{C}$ ) out to at least 2100 . The most important result, however, in accord with the above authors, is that, unless leakage rates for new methane can be kept below $2 \%$, substituting gas for coal is not an effective means for reducing the magnitude of future climate change. This is contrary to claims such as that by Ridley (2011) who states (p. 5), with regard to the exploitation of shale gas, that it will "accelerate the decarbonisation of the world economy". The key point here is that it is not decarbonisation per se that is the goal, but the attendant reduction of climate change. Indeed, the shorter-term effects are in the opposite direction. Given the small climate differences between the baseline and the coal-to-gas scenarios, decisions regarding further exploitation of gas reserves should be based on resource availability (both gas and water), the economics of extraction, and environmental impacts unrelated to climate change. 
Acknowledgments Comments from Chris Green and the external reviewers helped improve the original version of this manuscript. The National Center for Atmospheric Research is supported by the National Science Foundation.

\section{References}

Clarke LE, Edmonds JA, Jacoby HD, Pitcher H, Reilly JM, Richels R (2007) Scenarios of Greenhouse Gas Emissions and Atmospheric Concentrations. Sub-report 2.1a of Synthesis and Assessment Product 2.1. A Report by the Climate Change Science Program and the Subcommittee on Global Change Research, Washington, DC, 154pp

EPA (2005) Compilation of Air Pollutant Emission Factors, vol. I, Stationary Point and Area Sources. Report AP-42, Office of Air and Radiation, U.S. EPA, Research Triangle Park, NC 27711

Hayhoe K, Kheshgi HS, Jain AK, Wuebbles DJ (2002) Substitution of natural gas for coal: Climatic effects of utility sector emissions. Climatic Change 54:107-139

Howarth RW, Santoro R, Ingraffea A (2011) Methane and the greenhouse-gas footprint of natural gas from shale formations. Climatic Change. doi:10.1007/s10584-011-0061-5

IPCC (2007) Summary for Policymakers. In: Solomon S, Qin D, Manning M, Chen Z, Marquis M, Averyt KB, Tignor M, Miller HL (eds) Climate change 2007: The Physical Science Basis; Contribution of Working Group I to the Fourth Assessment Report of the Intergovernmental Panel on Climate Change. Cambridge University Press, pp 1-18

Meinshausen M, Raper SCB, Wigley TML (2011) Emulating coupled atmosphere-ocean and carbon cycle models with a simpler model, MAGICC6 - Part I: model description and calibration. Atmos Chem Phys $11: 1417-1456$

Nakićenović N, Swart R (eds) (2000) Special report on emissions scenarios. Cambridge University Press, Cambridge, $570 \mathrm{pp}$

Ridley M (2011) The shale gas shock. GWPF Report 2, Global Warming Policy Foundation, London, UK, $34 \mathrm{pp}$

Smith SJ, Wigley TML (2000a) Global warming potentials: 1. Climatic implications of emissions reductions. Climatic Change 44:445-457

Smith SJ, Wigley TML (2000b) Global warming potentials: 2. Accuracy. Climatic Change 44:459-469

Spath PL, Mann MK, Kerr DR (1999) Life cycle assessment of coal-fired power production. National Renewable Energy Laboratory Technical Paper, NREL/TP-570-25119, 172pp

Wigley TML (1991) Could reducing fossil-fuel emissions cause global warming? Nature 349:503-506

Wigley TML, Clarke LE, Edmonds JA, Jacoby HD, Paltsev S, Pitcher H, Reilly JM, Richels R, Sarofim MC, Smith SJ (2009) Uncertainties in climate stabilization. Climatic Change 97:85-121. doi:10.1007/s10584009-9585-3 